Review Article

\title{
Acute Hepatic Porphyria
}

\author{
D. Montgomery Bissell* and Bruce Wang
}

Division of Gastroenterology, University of California, San Francisco, CA, USA

\begin{abstract}
The porphyrias comprise a set of diseases, each representing an individual defect in one of the eight enzymes mediating the pathway of heme synthesis. The diseases are genetically distinct but have in common the overproduction of heme precursors. In the case of the acute (neurologic) porphyrias, the cause of symptoms appears to be overproduction of a neurotoxic precursor. For the cutaneous porphyrias, it is photosensitizing porphyrins. Some types have both acute and cutaneous manifestations. The clinical presentation of acute porphyria consists of abdominal pain, nausea, and occasionally seizures. Only a small minority of those who carry a mutation for acute porphyria have pain attacks. The triggers for an acute attack encompass certain medications and severely decreased caloric intake. The propensity of females to acute attacks has been linked to internal changes in ovarian physiology. Symptoms are accompanied by large increases in delta-aminolevulinic acid and porphobilinogen in plasma and urine. Treatment of an acute attack centers initially on pain relief and elimination of inducing factors such as medications; glucose is administered to reverse the fasting state. The only specific treatment is administration of intravenous hemin. An important goal of treatment is preventing progression of the symptoms to a neurological crisis. Patients who progress despite hemin administration have undergone liver transplantation with complete resolution of symptoms. A current issue is the unavailability of a rapid test for urine porphobilinogen in the urgent-care setting.
\end{abstract}

(C) 2015 The Second Affiliated Hospital of Chongqing Medical University. Published by XIA \& HE Publishing Ltd. All rights reserved.

\footnotetext{
Keywords: Porphyria; Porphobilinogen; Delta-aminolevulinic acid.
}

Abbreviations: AIP, acute intermittent porphyria; ALA, delta-aminolevulinic acid; ALAD, delta-aminolevulinic dehydratase; ALAS, delta-aminolevulinic acid synthase; APF, American Porphyria Foundation; CLIA, Clinical Laboratory Improvement Amendments; CNS, central nervous system; COPRO, coproporphyrin; CPOX, coproporphyinogen oxidase; CYP, cytochrome P450; DNA, deoxyribonucleic acid; ED, Emergency Department; EPNET, European Porphyria Network; GnRH, gonadotropin releasing hormone; HCP, hereditary coproporphyria; HGMD, Human Gene Mutation Database; HMBS, hydroxymethylbilane synthase; ICU, intensive care unit; IV, intravenous; PBG, porphobilinogen; PPOX, protoporphyrinogen oxidase; PROTO, protoporphyrin; RNAi, ribonucleic acid interference; SIADH, syndrome of inappropriate antidiuretic hormone secretion; URO, uroporphyrin; VP, variegate porphyria.

Received: 15 December 2014; Revised: 20 January 2015; Accepted: 21 January 2015

DOI: $10.14218 / \mathrm{JCTH} .2014 .00039$

*Correspondence to: D. Montgomery Bissell, University of California, Box 0538 513, Parnassus Avenue, San Francisco, CA 94143-0538, USA. Tel: +1-415-4768405, Fax: +1-415-476-0659, E-mail: montgomery.bissell@ucsf.edu

\section{Introduction}

The first reports of clinical porphyria appeared in the 1870's, describing patients who excreted porphyrin-like chemicals and had symptoms ranging from abdominal pain to photosensitivity. Some had disfiguring photocutanous damage with loss of tissue from the ears, eyelids and fingers, in association with very high urine porphyrins. One patient was hired as a laboratory assistant for Hans Fischer, a German physician and chemist, and provided urine from which the chemical structure of uroporphyrin was deduced. Fischer then synthesized the compound de novo. In the process he established the structures of bilirubin and heme, respectively, work for which he received the Nobel Prize in Chemistry in 1930. Studies of heme synthesis in living organisms followed, starting in the 1940s, facilitated by the advent of isotopic tracer techniques. ${ }^{1}$ By the 1960 s, the pathway was well delineated, allowing predictions of the specific enzyme deficiency associated with each of the porphyrias. ${ }^{2}$ The predictions were confirmed initially with assay of the individual enzymes, then by deoxyribonucleic acid (DNA) analysis of the relevant genes.

Studies of heme physiology proceeded in parallel with clinical genetics. The bone marrow was long understood as a major site of heme synthesis, largely for hemoglobin production. Work starting in the 1960 s showed that the liver was another active producer of heme, mainly for the cytochrome P450 (CYP) family of heme proteins, which mediate the inactivation and elimination of many drugs. CYP induction was demonstrated in rodents given drugs that are metabolized by this group of cytochromes. ${ }^{3}$ It was shown also that the initial enzyme of the pathway, delta-aminolevulinic acid (ALA) synthase (ALAS), is subject to feedback regulation by heme (Fig. 1), which led to the hypothesis that the acute porphyrias represent a state of relative or actual heme deficiency in hepatocytes. This became the rationale for treatment of acute porphyria by hemin* infusion, starting in $1971 .{ }^{4}$ Given the rarity of acute attacks of porphyria, safety and efficacy information built slowly, case by case. By the late 1980s, however, a consensus existed, and a commercial formulation was developed (Panhematin ${ }^{\circledR}$ ). It was the first therapeutic approved under the U.S. Orphan Drug Act of 1983.

\footnotetext{
* The term heme denotes iron-protoporphyrin-IX without respect to the oxidation state of the iron moiety (ferric vs, ferrous). Heme extracted from blood is ferriheme, or hemin, with a chloride counter-ion. Solubilization of hemin for infusion requires a mildly alkaline buffer in which chloride is replaced by hydroxyl ion. In this form, the chemical is termed hematin.
} 


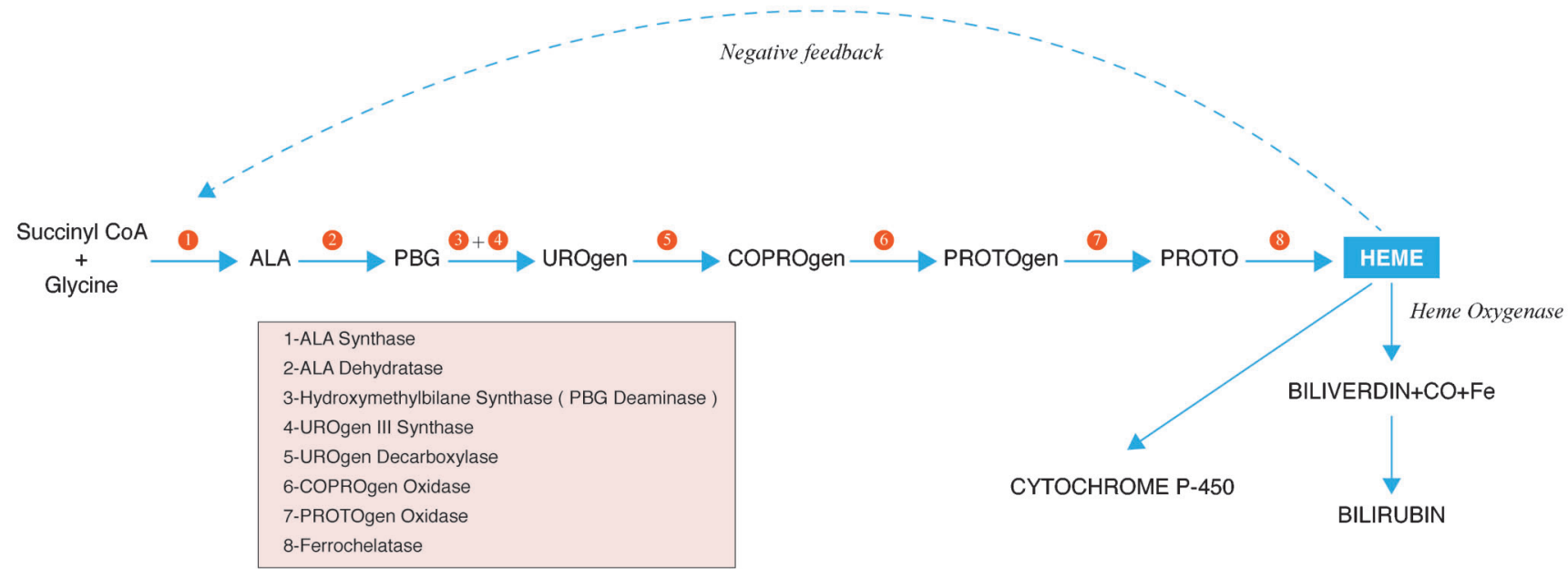

Fig. 1. The pathway of heme synthesis and the enzymes mediating specific steps. The building blocks of heme are succinyl CoA and glycine, which combine to form delta-aminolevulinic acid (ALA), the first committed intermediate of the pathway. ALA synthase is encoded by two distinct genes: ALAS2 in the bone marrow and ALAS1 elsewhere, including the liver (see text). The second step involves condensation of two molecules of ALA to form porphobilinogen (PBG), the pyrrole subunit of the heme ring. Four PBGs are linked initially in a linear tetrapyrrole, hydroxymethylbilane, which cyclizes to form the initial porphyrin of the pathway, uroporphyrinogen (UROgen). The sequential conversion of UROgen to coproporphyrinogen (COPROgen) and finally to protoporphyrinogen (PROTOgen) involves successive removal of peripheral carboxyl groups. The dashed arrow indicates that the end-product, heme, exerts feedback regulation on the formation of ALA, the initial committed intermediate. The gene symbols for the pathway enzymes are noted in Table 1.

ALA, delta-aminolevulinic acid; PBG, porphobilinogen; URO, uroporphyrin; COPRO, coproporphyrin; PROTO, protoporphyrin.

\section{Pathway of heme synthesis}

The initial intermediates, ALA and porphobilinogen (PBG), are water soluble. The porphyrins, from uroporphyrin (URO) to protoporphyrin (PROTO), are increasingly lipophilic as a result of successive decarboxylation. The differences in chemical properties are reflected in their routes of excretion. The water-soluble intermediates, including URO, appear exclusively in urine. Coproporphyrin, with four carboxyl groups (four fewer than uroporphyrin), is cleared by both the liver and the kidneys. The final porphyrin in the pathway, PROTO with two carboxyl substituents, is highly lipophilic and not detectable in urine. It is taken up by the liver, excreted into bile, and eliminated in feces. The heme pathway normally is highly efficient, with only a minute fraction of the total precursor flux leaving the pathway to undergo excretion.

\section{Regulation of heme and porphyrin synthesis}

Each step in heme synthesis is catalyzed by an individual enzyme, which vary in their capacity. The rate-limiting step for the pathway as a whole is the formation of ALA, which is catalyzed by ALAS (Fig. 1). Two forms of ALAS exist and are distinct gene products. ${ }^{5}$ One is present in all tissues except the bone marrow, is particularly active in the liver (for CYP production), and is known as ALAS1 (human chromosome 3 ). The erythroid form, ALAS2, is on the X chromosome and serves hemoglobin synthesis. Hepatic ALAS1 is produced in the cytosol. It then translocates into mitochondria where ALA is formed. When hemin is administered for an attack of acute porphyria, it expands the intracellular regulatory heme pool in hepatocytes, activating feedback inhibition of ALAS1 (Fig. 1) and reducing the flow of ALA and subsequent precursors into the pathway. ${ }^{6}$ Conversely, when circumstances call for an increase in hepatic CYP (for example, after administration of an inducing medication), the intracellular heme pool becomes depleted. This lifts the feedback inhibition of ALAS, allowing the flow of heme precursors to increase. In most individuals with an inherited defect in heme synthesis, the capacity of the pathway appears to be sufficient for homeostatic heme replacement. In some, however, it is inadequate for meeting a demand for increased production. In the latter situation the result is hyperinduction of ALAS and, often, symptoms of acute porphyria. It should be noted that the erythroid form, ALAS2 is regulated by iron rather than heme and is not affected by inducers of ALAS1. Thus, the acute porphyrias involve nonerythroid tissues exclusively and, of the latter, mainly the liver because of its high concentration of microsomal cytochromes.

\section{Genetics of porphyria}

Three of the acute hepatic porphyrias (acute intermittent porphyria (AIP), hereditary coproporphyria (HCP), and variegate porphyria (VP)) are autosomal dominant disorders, affecting males and females equally. A fourth type, deltaaminolevulinic aciduria (ALAD), is autosomal recessive and very rare. ${ }^{7}$ For the three dominant types, family studies with DNA analysis have indicated multiple mutations. ${ }^{8-10}$ For AIP, 391 distinct mutations in hydroxymethylbilane synthase (HMBS) have been reported as of November 2014; for HCP, the number of coproporphyinogen oxidase (CPOX) mutations is 65 ; and for $\mathrm{VP}$, the number in protoporphyrinogen oxidase (PPOX) is 177 (Human Gene Mutation Database (HGMD)Biobase ${ }^{\circledR}$ ). While enzyme activity varies with the nature of the mutation, on average it is roughly $50 \%$ of normal. Efforts to associate specific mutations with clinical manifestations have been largely negative. ${ }^{11,12}$ Regardless of genotype, the vast majority (perhaps 90\%) of confirmed genetic carriers never experience an attack. In families with multiple documented genetic carriers, symptoms often are limited to one or two individuals. This highlights the importance of environmental, metabolic, and genetic cofactors in the pathogenesis of acute attacks. ${ }^{13}$ 
Acute porphyria exists in all ethnic and racial groups, worldwide. For reasons of isolation in the past, northern Scandinavia and South Africa have an unusually high prevalence of AIP and VP, respectively. Consistent with a founder effect, the number of discrete mutations in these populations is limited. ${ }^{14}$ In South Africa, VP was introduced by a Dutch settler arriving in 1688 and now affects approximately 20,000 people, of whom more than $90 \%$ carry the R59W mutation. ${ }^{15}$

\section{Heme precursor patterns in acute porphyria and genetic diagnosis}

Fig. 1 shows the profile of heme precursors in urine or feces for the four hepatic porphyrias. The pattern is distinctive for each type, reflecting the step that is genetically altered. The route of precursor excretion (urine or bile/feces) reflects the relative lipophilicity of the individual precursors, as noted above. Before the advent of genetic analysis, the enzymatic defect for each of the porphyrias was predicted from these patterns and confirmed by assays of enzyme activity. In AIP, the altered gene product, HMBS (also known as PBG deaminase or uroporphyrinogen-1 synthase), exists in two forms, which arise by alternative splicing of the primary transcript; the erythroid HMBS gene transcript lacks exon 2 of the hepatic transcript. ${ }^{16}$ Because the enzyme is cytosolic, it persists in erythrocytes. ${ }^{17}$ A commercial blood test was developed, which is used together with urine tests to diagnose AIP. Its main shortcoming is partial overlap of the normal and deficient ranges. ${ }^{18}$ Also, it yields a false-negative result when the HMBS mutation is in exon 2, which the erythroid-specific transcript lacks. Finally, sample handling problems may allow decay of the activity and a false-positive result. Overall, the HMBS assay identifies about $80 \%$ of AIP carriers. Enzyme tests for HCP (CPOX) and VP (PPOX), respectively, are not available commercially. An assay for CPOX in whole blood was offered in the 1990s but resulted in many false-positive results and ultimately was discontinued. ${ }^{19}$

Assessment of the biochemical profile remains the primary method for evaluating the type of acute porphyria in an individual case, but a new diagnosis should be confirmed by mutation analysis of the suspect gene. With current methods, the genetic lesion can be defined in $>95 \%$ of cases. ${ }^{20}$ Given that many asymptomatic carriers exhibit no biochemical signs, DNA analysis is the most effective screening method when the family mutation is known, and it can be performed with a small sample - buccal brushing or saliva. For reasons of cost, it is not recommended for individuals whose symptoms are suggestive of porphyria but whose urinary and fecal biochemistry is normal or nondiagnostic. The number of positive results will be exceedingly low, and finding a mutation does not mean that porphyria is the cause of the patient's complaints in the absence of abnormal urine biochemistry.

\section{Classification of porphyrias}

The porphyrias are grouped according to their predominant manifestation (neurologic or cutaneous) and the tissue that is the main source of porphyrin overproduction (liver or bone marrow) (Fig. 2; Table 1). The liver gives rise to the four acute neurovisceral porphyrias and to porphyria cutanea tarda, a relatively common cutaneous porphyria. The erythron is the source of porphyrin overproduction for two cutaneous porphyrias, congenital erythropoietic porphyria and protoporphyria. In cutaneous porphyria, porphyrins in the skin undergo activation by light in the blue spectrum, not UV (peak excitation $410 \mathrm{~nm}$ under physiological conditions).

\section{Prevalence of acute hepatic porphyria}

The prevalence of AIP has been estimated at 5-10 cases per 100,000 . However, this is based largely on people with symptoms, who represent only a small fraction of those who carry a relevant mutation and are at risk of an attack. In one study of mutation prevalence from France, 3,350 healthy blood donors were screened for HMBS (PBG deaminase) deficiency. The test was positive in four, and a known AIP mutation was documented in two. ${ }^{21}$ Thus, the prevalence of mutations in this group was at least $1: 1,675(60: 100,000)-$ far larger than is generally assumed. Another study from northwestern Russia (St. Petersburg) and Finland screened patients who were admitted to a neurology ward with acute polyneuropathy or encephalopathy and abdominal pain. Out of 108 patients, $11 \%$ proved to have previously undiagnosed acute porphyria. ${ }^{22}$ While these studies are small, they suggest that people coming to an Emergency Department (ED) with recent onset abdominal pain may have a mutation for AIP more often than is generally assumed. ${ }^{23}$

\section{Pathophysiology of neurovisceral pain in acute porphyria}

The metabolic changes underlying acute porphyria have been well-delineated for more than 40 years, yet for most of that time their role in the pathogenesis of neurovisceral attacks has been unclear. Research has focused on two hypotheses that are not mutually exclusive. The first is heme deficiency, which could directly affect neuronal function in that these cells, like hepatocytes, require heme for synthesis of essential heme proteins. One such protein is tryptophan pyrrolase, which has a relatively low affinity for heme but requires it for enzymatic activity. When heme is scarce, the activity drops, potentially shifting tryptophan metabolism from the kynurenine pathway to 5-hydroxytryptamine (serotonin), a neurotransmitter. Although certain aspects of acute porphyria suggest a serotonergic state, human data to confirm this postulate are lacking. ${ }^{24}$

The second hypothesis concerns neuropathological effects of ALA and/or PBG, both of which increase with ALAS1 induction. Experimental models have shown that ALA generates oxidant stress, implying potential for direct neurotoxicity. ${ }^{25}$ Recent clinical observations have further implicated ALA in the symptoms of acute attacks. Two other diseases, hereditary tyrosinemia and lead poisoning present with neurovisceral symptoms that closely resemble those of acute porphyria. Both conditions perturb heme synthesis by partially inactivating ALA dehydratase, causing selective overproduction of ALA but not PBG. ${ }^{26-28}$ In 2005 , selective reduction of PBG levels in people with porphyria was explored by administering recombinant human PBG deaminase (Porphozyme ${ }^{\circledR}$ ). Phase 1 studies of asymptomatic patients with AIP demonstrated a rapid drop in PBG after a single dose of the medication, followed by a return to baseline after $12 \mathrm{~h} .{ }^{29}$ In unpublished studies of patients with symptoms, the drug had no effect, although the frequency of dosing and total duration of treatment probably were suboptimal. In 2004, the first liver transplant was performed for a patient with severe recurrent attacks, chronically high ALA and PBG 


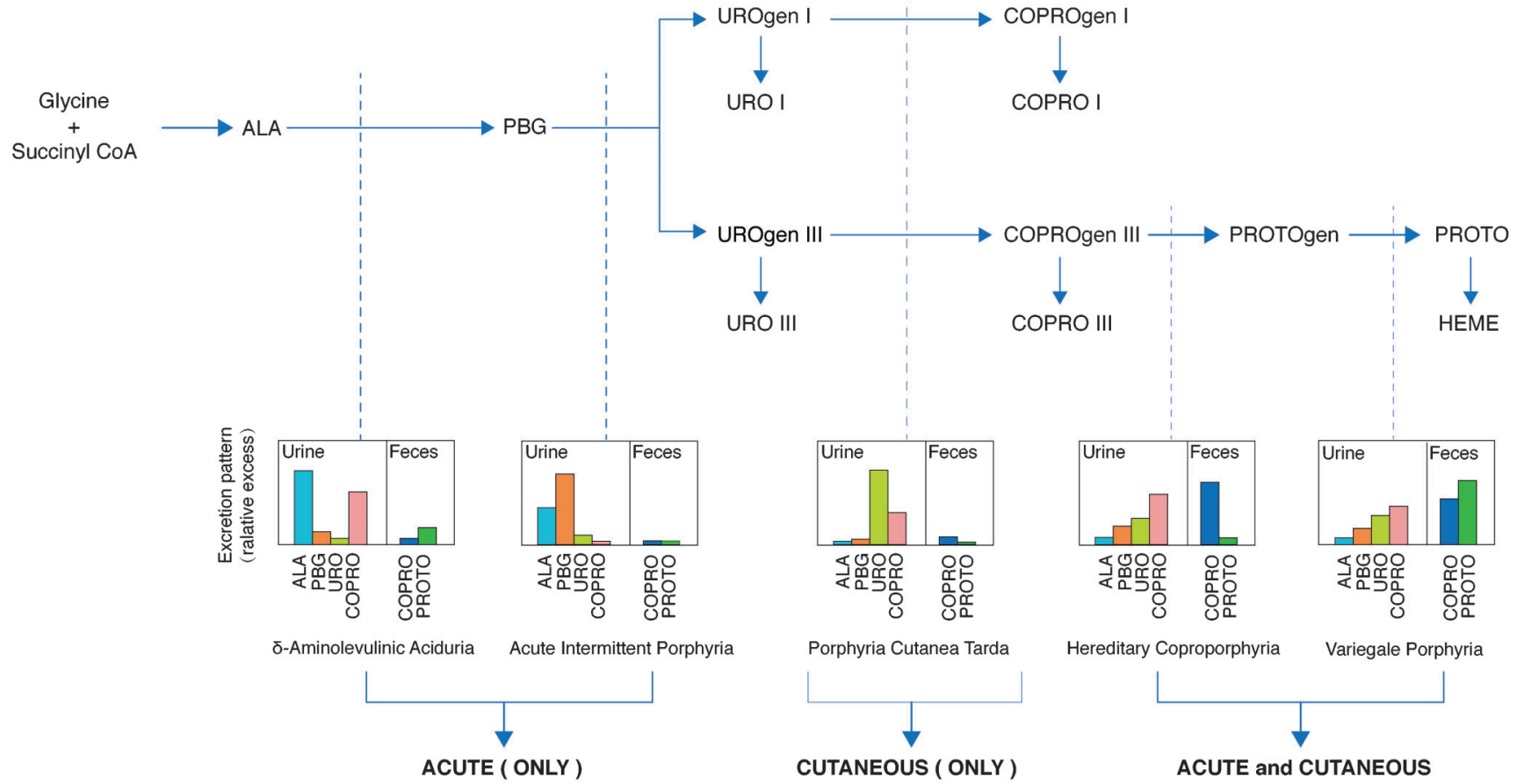

Fig. 2. The profile of heme precursors in excreta for each of the hepatic porphyrias. The dashed vertical lines indicate the point at which an inherited enzyme deficiency compromises the flow of precursors. For the specific enzymes affected and key to abbreviations, see Fig. 1. [Not shown: The respective patterns for ALAD (very rare, homozygous recessive acute porphyria), congenital erythropoietic porphyria (rare recessive cutaneous porphyria), and protoporphyria (recessive cutaneous porphyria, in which $\sim 5 \%$ of cases have liver disease from protoporphyrin deposition.]

and apparent resistance to intravenous hemin. The ALA and PBG normalized within a few days after the surgery, and the symptoms resolved. ${ }^{30}$ Taken together, these data implicate ALA as the pathogenic molecule in acute porphyria.

\section{The acute attack - clinical manifestations}

The symptoms individually are nonspecific but in aggregate may suggest the diagnosis (Table 2 ). Attacks occur mainly in

Table 1. Classification of the porphyrias

\begin{tabular}{|c|c|c|c|}
\hline $\begin{array}{c}\text { Name } \\
\text { (abbreviation and MIM phenotype \#) }\end{array}$ & $\begin{array}{l}\text { Mutated gene } \\
\text { (symbol) }\end{array}$ & $\begin{array}{l}\text { Acute neurovisceral } \\
\text { symptoms }\end{array}$ & $\begin{array}{l}\text { cutaneous } \\
\text { symptoms }\end{array}$ \\
\hline $\begin{array}{c}\text { Delta-aminolevulinic Aciduria } \\
\text { (ALAD, 125270) }\end{array}$ & $\begin{array}{c}\text { ALA dehydratase* } \\
\text { (ALAD) }\end{array}$ & +++ & 0 \\
\hline $\begin{array}{l}\text { Acute Intermittent Porphyria } \\
(\text { AIP, 176000) }\end{array}$ & $\begin{array}{c}\text { Hydroxymethylbilane synthase } \\
\text { (HMBS) }\end{array}$ & +++ & 0 \\
\hline $\begin{array}{l}\text { Congenital Erythropoietic } \\
\text { Porphyria (CEP, 263700) }\end{array}$ & $\begin{array}{l}\text { UROgen III synthase } \\
\text { (UROS) }\end{array}$ & 0 & +++ \\
\hline $\begin{array}{c}\text { Porphyria Cutanea Tarda } \\
\text { (PCT, 176100) }\end{array}$ & $\begin{array}{l}\text { UROgen decarboxylase }{ }^{* *} \\
\text { (UROD) }\end{array}$ & 0 & + \\
\hline $\begin{array}{l}\text { Hereditary Coproporphyria } \\
\qquad(\mathrm{HCP}, 121300)\end{array}$ & $\begin{array}{l}\text { COPROgen oxidase } \\
\text { (CPOX) }\end{array}$ & ++ & + \\
\hline $\begin{array}{l}\text { Variegate Porphyria } \\
\quad(\mathrm{VP}, 176200)\end{array}$ & $\begin{array}{l}\text { PROTOgen oxidase } \\
\text { (PPOX) }\end{array}$ & ++ & + \\
\hline $\begin{array}{l}\text { Erythropoietic Protoporphyria } \\
\text { (EPP, 177000) }\end{array}$ & $\begin{array}{l}\text { Ferrochelatase* } \\
\text { (FECH) }\end{array}$ & 0 & ++ \\
\hline $\begin{array}{l}\text { X-Linked Protoporphyria } \\
\text { (XLP, 300752) }\end{array}$ & $\begin{array}{l}\text { ALA synthase-2 } \\
\text { (ALAS2) }\end{array}$ & 0 & ++ \\
\hline
\end{tabular}

*ALAD and CEP are autosomal recessive diseases and very rare. EPP is recessive but more prevalent than ALAD or CEP. In most individuals, one ferrochelatase allele carries a structural mutation while the other has a common 'hypomorphic' mutation with a variable (often minor) effect on gene expression. The latter mutation by itself causes no disease, even when homozygous. The other porphyrias are dominantly inherited, with variable penetrance.

** $20-25 \%$ of individuals with PCT have a mutation in the UROgen decarboxylase gene. The remainder are said to have 'sporadic' PCT. In the latter group, hepatic UROgen decarboxylase protein is normally abundant, but its activity is low. Studies have pointed to uroporphomethene, a product of UROgen oxidation, as a possible inhibitor. ${ }^{54}$ 
Bissell D.M. et al: Acute hepatic porphyria

Table 2. Typical presentation of acute hepatic porphyria

Female, age 15-45, demanding pain medication

Abdominal or back pain of increasing severity over $>2$ days, poorly localized by exam

Nausea, unable to take anything by mouth

Generalized seizure (present in 10-20\%)

No fever or leukocytosis

Investigation: hyponatremia and mildly elevated transaminases (not present in all cases); negative pregnancy test; negative abdominal imaging except for ileus

Previous ED presentation with similar symptoms, without a specific diagnosis

females age 15 to 45 . They are rare prior to menarche and become less likely after menopause. The most common symptom is abdominal pain, which is usually diffuse. In some patients, it is localized to the back or an extremity. By the time the patient is seen, pain has increased relentlessly for several days, not hours, often accompanied by nausea, vomiting, and constipation. Fever and leukocytosis are not present in the absence of an accompanying infectious process. Mild elevation of the transaminases is common. Hyponatremia may be seen and occasionally is severe. Because patients tend to present dehydrated after several days of nausea and inadequate oral intake, hyponatremia may be masked initially by hemoconcentration but can develop rapidly after rehydration with dextrose in water. The pathophysiology is debated. In some cases it appears to be a form of inappropriate $A D H$ secretion (syndrome of inappropriate antidiuretic hormone secretion (SIADH)) due to pituitary central nervous system (CNS) dysfunction; urine osmolarity can be high, consistent with SIADH. In others, hypovolemia may be the underlying problem.

In an attack that has not been recognized and treated, acute visceral symptoms may progress to motor neuropathy, which is manifested initially as weakness of the proximal limb muscles but in advanced cases the respiratory muscles as well. Seizures occur in $10-20 \%$ of cases. Patients presenting with seizure represent a difficult challenge for the consulting neurologist. If acute porphyria is not considered, the treatment may include medications such as phenytoin or valproic acid, which intensify the attack with potentially disastrous results. ${ }^{31}$ For this reason, early diagnosis is critical, followed by definitive treatment with intravenous hemin (Panhematin ${ }^{\circledR}$ or Normosang ${ }^{\mathbb{R}}$, Recordati Rare Diseases). ${ }^{32,33}$ Seizures in acute porphyria can be controlled with a short-acting benzodiazepine, gabapentin, or magnesium. ${ }^{34-36}$ For a patient with refractory seizures, anesthesia with propofol is safe. ${ }^{37,38}$

\section{Biochemical diagnosis of acute porphyria}

In all three autosomal dominant acute porphyrias, attacks are accompanied by a clear increase in PBG (Fig. 2), which, for convenience, is generally assessed in urine rather than blood. In active AIP, the type most commonly associated with acute attacks, the PBG is at least 10 -fold the upper limit of normal, more typically 20 - to 100 -fold. A urine PBG of $>50 \mathrm{mg} / \mathrm{g}$ creatinine (normal $<2$ ) in a patient with pain symptoms of unknown cause is highly specific for the diagnosis; occasional genetic carriers have PBG levels in this range even when feeling well and thus represent false-positive cases. While this is unusual, it highlights the importance of having baseline information from urine samples that are collected when the patient is feeling well. ALA should be evaluated at the same time to identify cases of lead poisoning, which can mimic acute porphyria. It would also identify the rare individual with ALA dehydratase deficiency.

For people who are known carriers of a porphyria mutation, determining whether symptoms represent a porphyria exacerbation or are due to a more common problem can be a diagnostic challenge. In those with recurrent attacks, the pattern of symptoms is largely reproduced with each episode, but urine PBG still should be evaluated for biochemical confirmation. A random urine sample is adequate, provided a urine creatinine is obtained, so that results can be expressed per gram creatinine. The sample should be collected prior to intravenous (IV) fluid resuscitation. If it is very dilute, it could yield a false-negative result.

\section{Diagnosis in the ED - the importance of urine PBG}

People having a first attack of acute porphyria generally present to an ED. Because the diagnosis has important implications for management, it should be made as early as possible, ideally while the patient is in the ED. However, rapid or urgent determination of urine PBG is rarely available. The consequences for patient management are illustrated by the following case:

A woman, age 24 , with no prior medical history presented to the ED of her community hospital with abdominal pain, nausea, and vomiting for the previous 4 days. The initial evaluation was negative, including physical exam, urine drug screen, and pregnancy test. A resident physician listed acute porphyria in the differential diagnosis and ordered a urine PBG. Further workup with complete laboratory tests, imaging, and endoscopy was negative. Endometriosis was considered but discarded because of the atypical presentation and lack of findings. In light of the patient's continuing demand for pain medication and lack of convincing physical findings, a psychiatric diagnosis was favored. She was managed symptomatically with opiates and antiemetics. After 10 days, she was felt to be improved and was discharged, still on pain medication. At home, her pain was poorly controlled, and after 3 days she returned to the ED. Coincidentally, the previously ordered urine test came back showing a markedly elevated PBG $(176 \mathrm{mg} / \mathrm{g}$ creatinine; reference range $<2)$. She was readmitted and given IV hemin daily for 4 days with complete resolution of symptoms.

Typically, acute porphyria is considered only after a patient has made several visits to the ED. ${ }^{23}$ In this case, it was on the list of possible diagnoses, and urine PBG was ordered. However, the turnaround time for the outside laboratory was 2 weeks. This essential information, therefore, was missing for the duration of the patient's initial hospitalization. Fortunately, the illness did not progress to neurological complications while the lab report was pending. 
The need for a rapid PBG test was recognized in the 1940's, and qualitative assays using Ehrlich's reagent were developed for ED staff. ${ }^{39-41}$ With implementation of the U.S. Clinical Laboratory Improvement Amendments (CLIA) in 1992, however, the rapid tests were deemed moderately complex, and their use was restricted to trained laboratory personnel. The CLIA legislation coincided with the rise of large commercial laboratories, which could offer specialty tests, such as those for porphyria, at a cost well below that of an individual hospital. Contracts were signed. In the transfer, however, only the routine quantitative PBG was retained. Today, none of the large U.S. reference labs provides a rapid test (website information from Quest, LabCorp, Mayo, ARUP, PAML (Spokane, WA, USA), TriCore, Lenco, and PeaceHealth). A PBG Kit was developed, which is a variation on the column method. ${ }^{42}$ Initial reports have indicated that it is superior to the Watson-Schwartz and its variations. ${ }^{43,44}$ However, these were small studies, and its performance characteristics remain unknown. The test is likely to overcome the limitations of the older qualitative tests in both sensitivity and specificity.

What is needed is a standard quantitative test that is available on an urgent or expedited basis. The concern of the laboratories is the cost of providing a service that may be requested only occasionally. However, the actual cost per positive test of implementing rapid PBG screening is unknown, because very little information exists on the prevalence of acute porphyria in the urgent care setting. An analysis from the Mayo Clinic concluded that a rapid PBG test would be cost-effective. ${ }^{45}$ While additional studies are needed, it should be noted that the cost of a delayed diagnosis is also high: multiple unnecessary procedures, prolonged hospitalization, and treatment for an erroneous diagnosis, including intensive care unit (ICU) care for those in neurological crisis.

\section{Missed diagnosis and misdiagnosis}

In the urgent care setting, porphyria is often overlooked as a diagnostic possibility, because the symptoms are those of far more common conditions. ${ }^{23}$ When the initial screening tests for the common conditions are negative, patients usually are discharged with a diagnosis of viral gastroenteritis, irritable bowel syndrome, addiction withdrawal, or psychosomatic pain. A recent study of U.S. patients with genetically confirmed acute porphyria found that the diagnosis was delayed by an average of 15 years from the onset of symptoms (as defined by the patient). ${ }^{46}$ The case presented above is unusual, in that a perceptive resident physician thought of the diagnosis and ordered the correct test, a urine PBG.

Misdiagnosis also occurs but in the outpatient rather than the ED. It arises when the gamut of tests and procedures has failed to identify a reason for the patient's chronic abdominal pain. Rare diseases then come under consideration, and a porphyrin screen is ordered. The latter consists of fractionated urine porphyrins only; it does not include ALA and PBG, which must be ordered separately. In some cases, the report shows elevation of several porphyrin fractions, predominantly COPROs. Although the changes are quantitatively minor (2to 4-fold the upper limit of normal) and well below the threshold for symptoms for cutaneous porphyria, the patient receives a diagnosis of porphyria and feels relief at having, at last, a name for the recurring symptoms. Unfortunately, elevation of urinary porphyrins in this range is nonspecific. If the PBG is normal, the porphyrin changes do not signify acute porphyria. They are seen most often in liver disease (of any cause, not necessarily severe) as well as in neurological and hematological problems. If a PBG has not been done, the patient should be instructed to collect a urine sample during a period of active symptoms. The timing is important because in carriers of a gene for acute porphyria, the PBG may be normal when the patient is symptom-free.

The number of people who have been misdiagnosed and believe, erroneously, that they have acute porphyria far exceeds those with a confirmed diagnosis. When they come to an ED, very few will have documentation of their diagnosis. In this situation, a rapid PBG would be definitive but, as discussed above, is not available. Although neurological complications are not a concern in this group, a test that excludes acute porphyria would redirect attention to other possible causes of the patient's complaints and potentially avoid an expensive and unproductive hospitalization.

\section{Treatment of acute porphyria}

Initial management is focused on eliminating factors that may be contributing to an attack, including inducer medications, caloric deprivation, and dehydration (Table 3). Medications considered risky for genetic carriers of acute porphyria and all nonessential medications are discontinued. The American Porphyria Foundation (APF) and the European Porphyria Network (EPNET) maintain lists of drugs that are considered safe or hazardous. If possible, calories and rehydration are administered orally to reverse the fasting state; otherwise, $10 \%$ dextrose in $0.45 \%$ normal saline is administered IV. Although this therapy has not been tested in controlled trials, it does stop the attack for some patients. Hyponatremia may be severe, requiring urgent saline administration. A protocol that minimizes the risk of brainstem damage should be followed. ${ }^{47}$ Pain relief generally requires opiates, often in large doses, while waiting for porphyriaspecific therapy to take effect (see below).

IV hemin (Panhematin ${ }^{\circledR}$ or Normosang ${ }^{\circledR}$ ) is the only specific therapy, to date, for an acute attack. The first patient to receive hemin, in 1971, was terminally ill with multiorgan failure. ${ }^{4}$ The treatment did not affect her course but did reduce serum ALA and PBG, encouraging additional trials in patients whose acute attacks were not responsive to carbohydrate administration. ${ }^{32,48,49}$ Current practice is to use the medication early, with the goal of preventing progression to neurological complications. Most hospital pharmacies do not stock it, but the distributor will provide it by overnight air express (for details, see the web site of the American Porphyria Foundation: www.porphyriafoundation.com).

The clinical response to hemin infusion is not immediate. It becomes apparent 3 to 4 days after starting, when the patient experiences complete relief of pain and analgesics can be discontinued without a taper. ${ }^{49}$ Patients having recurrent attacks may request opiates to take at home because of anxiety about the next one. They should be advised that opiates will not prevent an attack and are indicated only for covering pain while waiting for specific therapy. The emphasis should be on active management with prophylactic hemin and the other measures described below.

Hemin infusion has some pitfalls that should be kept in mind. Particularly important is the instability of the solution. The commercial preparation, Panhematin ${ }^{\circledR}$, is a dry powder with a shelf life of several months, which is reconstituted with 
Bissell D.M. et al: Acute hepatic porphyria

Table 3. Protocol for Panhematin ${ }^{\circledR}$ infusion

Order five vials of Panhematin ${ }^{\circledR}$ (Recordati Rare Diseases Inc, USA)

Establish IV access using either a large peripheral vein or a central line

Determine the patient's total dose of Panhematin ${ }^{\mathbb{R}}$, based on $3-4 \mathrm{mg} / \mathrm{kg}$ body weight. Each vial contains $313 \mathrm{mg}$ with a concentration of $7 \mathrm{mg} / \mathrm{mL}$ after reconstitution. Example: a woman of $70 \mathrm{~kg}$ will receive $250 \mathrm{mg}$ or $35 \mathrm{~mL}$ of the freshly prepared solution.

At the bedside, add sterile water to the powder in the vial and agitate gently for 2 minutes. The liquid is black. Withdraw the volume not needed for the patient, and discard it. Without further delay, begin infusing the remainder of the vial using a line with a filter to capture any particles. The infusion rate is $1-1.5 \mathrm{~mL}$ per minute.

At the end of the infusion, flush the line with normal saline.

sterile water immediately prior to use. In liquid form, it decays to an inactive product with a half-life of less than $4 \mathrm{~h}$ at room temperature (slightly longer at $4{ }^{\circ} \mathrm{C}$ )..$^{50,51}$ It cannot be stored or reused. The biological activity of IV hemin is assessed by serial measurement of urinary PBG. A drop in PBG after 2 days of infusion to less than $20 \%$ of the pretreatment level confirms that the hemin was active.

The procedure for hemin infusion is outlined in Table 3. A large peripheral vein or a central line is required. The solution is slightly alkaline and can cause a painful phlebitis if infused into a small vein. The powder is reconstituted with sterile water, preferably at the bedside to avoid a delay in starting the infusion. In some centers, hemin is reconstituted with human albumin, ${ }^{52}$ which reduces the risk of phlebitis but does not affect decay of the compound. In Europe and South Africa, heme arginate (Normosang ${ }^{\circledR}$ ) is available. It is stable in $40 \% 1,2$-propanediol and $10 \%$ ethanol, and its efficacy is similar to that of Panhematin. ${ }^{53}$ Oral hemin is ineffective. ${ }^{32}$

The second pitfall is giving hemin when acute porphyria is not the diagnosis (see above: "Biochemical Diagnosis"). Some of the reported treatment failures may have been due to misdiagnosis. In a study of hemin infusion and a controlled trial of heme arginate, the patients clearly had acute porphyria, and both medications produced convincing decreases in ALA and PBG, but a symptomatic response was not seen consistently. ${ }^{54,55}$ In such patients, the symptoms may be due to something other than acute porphyria or related to previous neurological injury, which is not responsive to hemin. ${ }^{56}$ In well-characterized acute attacks treated with hemin that has been handled correctly, the clinical response is sufficiently predictable and striking that it may serve as a diagnostic test. If four days of infusion have little or no effect on symptoms (despite a drop in urine PBG), causes other than acute porphyria should be considered. ${ }^{49}$

Chemical phlebitis has been seen in approximately $4 \%$ of infusions of Panhematin ${ }^{\circledR}$ without albumin; ${ }^{48}$ it is less of a problem with Normosang but still occurs. ${ }^{55}$ It can be avoided by use of a slow infusion rate and a central line. Adverse effects other than phlebitis are infrequent. An accidental overdose produced transient renal failure in one patient. ${ }^{57} \mathrm{An}$ overdose of heme arginate in another patient led to acute liver failure requiring urgent transplant. ${ }^{58}$ One case of an anaphylactic reaction to heme arginate has been reported, possibly involving the propanediol component. ${ }^{59}$ Anticoagulant effects, prolonged prothrombin time and reduced platelets, have been reported. ${ }^{60,61}$ The abnormalities were transient and have not been linked to clinically significant bleeding. Nonetheless, caution is recommended when administering hemin to a patient with impaired coagulation or a bleeding tendency. Finally, iron accumulation can be seen. A typical
$200 \mathrm{mg}$ dose of hemin contains about $17 \mathrm{mg}$ of iron, which is released during conversion of heme to bile pigment, largely in hepatocytes. Patients receiving long-term prophylactic hemin are at risk of hepatic iron overload. The problem can be tracked with a serum ferritin every 6-12 months and treated as needed with phlebotomy or an oral chelator, to bring the serum ferritin below $500 \mathrm{ng} / \mathrm{mL}$.

\section{Management of frequent attacks}

In a few cases, which fortunately are uncommon, attacks become frequent and persist for many months or a few years. Their periodicity varies. Most cases are in women, and in some the symptoms occur monthly, 2-4 days prior to menstruation. Ovulatory suppression with a gonadotropin releasing hormone analog may be helpful. ${ }^{62,63}$ Oral contraceptives are generally avoided because of their association with acute attacks in some users (probably due to the progestational component). When attacks are frequent and predictable, the mainstay of treatment is prophylactic hemin infusion at an interval providing reasonable control of symptoms. ${ }^{13,64}$ For some patients, a single monthly infusion is effective. For others, one to three infusions per week may be needed.

When symptoms progress with neurological involvement despite ovulatory suppression and/or prophylactic hemin, liver transplant becomes a consideration. The first, performed in 2004 , appeared to be curative. ${ }^{30}$ It was followed by another dozen cases with similar results, ${ }^{65}$ including one in the U.S. at Mt. Sinai Medical Center, New York City (R.D. Desnick, personal communication). A cautionary note has come from the British experience, which found an unusually high incidence of post-transplant hepatic artery thrombosis (4 of 10 cases arising 3 days to 9 months after transplant). ${ }^{66}$ The $40 \%$ rate of this complication contrasts with a rate of $3-$ $5 \%$ for liver transplant as a whole. An AIP liver has been placed in a patient without other possibilities for transplant and caused symptoms suggestive of acute porphyria. ${ }^{67}$ The optimal timing of liver transplant is an unresolved issue. ${ }^{68}$ Recurring attacks cease spontaneously but unpredictably, and their frequency decreases as women enter menopause. Thus, premature liver transplant is a concern. On the other hand, patients who become severely disabled by neuropathy (on a respirator and/or receiving high doses of opiates) may be denied transplant, for reasons of difficult postsurgical management and increased mortality. Longitudinal study of individuals with frequent acute episodes is needed.

Molecular therapies are being developed at the present time. One strategy is ribonucleic acid interference (RNAi) to knock down ALAS1 mRNA. The objective is to reduce the 
overproduction of ALA that may cause symptoms in acute porphyria. ${ }^{69}$ Gene replacement therapy directed at hydroxymethylbilane synthase (PBG deaminase) deficiency also is being explored. ${ }^{70}$ Early human studies are under way for both of these approaches.

\section{Prognosis}

Fifty years ago, the outlook for acute porphyria with neurological complications was poor, with a reported mortality of $35 \% .{ }^{71}$ Although the prognosis remains guarded, the number of cases progressing to advanced disease has declined, as a result of heightened awareness, early identification of genetic carriers, and specific therapy in the form of hemin infusion. ${ }^{72,73}$ In patients with neuropathy who respond to treatment, motor deficits resolve slowly but usually completely, over an average of 10-11 months. ${ }^{71}$

Because the manifestations of an attack can include an altered mental state, there has been speculation that people with undiagnosed acute porphyria may be institutionalized for psychiatric reasons. One study indeed found an unexpectedly high prevalence of elevated urine PBG in residents of a mental health facility, ${ }^{74}$ albeit without symptoms suggestive of acute porphyria. When the question was reexamined, abnormal tests were no more frequent than expected. ${ }^{75}$ In patients with known porphyria who have been monitored long-term, to date there has been no evidence for excess chronic mental illness. ${ }^{76}$

Other late complications of acute porphyria, however, have been documented, including renal insufficiency, 77,78 subclinical liver disease, and primary liver cancer. ${ }^{79-82}$ The pathogenesis is being evaluated currently but may be related to chronically elevated blood ALA. If this is correct, genetic carriers with normal urine biochemistry are not at risk for these complications. The risk of liver cancer appears to be age-related and probably is higher in those with ongoing liver injury (as indicated by elevated transaminases) than in those with a completely normal liver panel and abdominal imaging. Currently, annual screening with liver imaging, such as ultrasound, and serum alpha-fetoprotein is recommended for known genetic carriers older than age 50 .

\section{Conclusions}

This review focuses on recent progress in the pathophysiology, diagnosis and treatment of the acute hepatic porphyrias. The need for rapid diagnosis of patients presenting with acute porphyria is highlighted.

\section{Acknowledgments}

Support was provided by an NIH grant (U54 DK083909) to the Porphyrias Consortium of the Rare Disease Clinical Research Network, Office of Rare Diseases Research, and by the UCSF Liver Center (P30 DK026743). Dr. Wang was supported by the American Porphyria Foundation's Protect the Future fund and by an individual NIH research training award (F32DK091005).

\section{Conflict of interest}

\section{Author contributions}

Writing the paper (DMB, BW).

\section{References}

[1] London IM, Shemin D, Rittenberg D. The study of hemoglobin metabolism in man with the aid of the isotope technique. J Clin Invest 1948;27:547.

[2] Meyer UA, Strand LJ, Doss M, Rees AC, Marver HS. Intermittent acute porphyria-demonstration of a genetic defect in porphobilinogen metabolism. N Engl J Med 1972;286:1277-1282. doi: 10.1056/NEJM197206152862401.

[3] De Matteis F, Gibbs A. Stimulation of liver 5-aminolaevulinate synthetase by drugs and its relevance to drug-induced accumulation of cytochrome P-450. Studies with phenylbutazone and 3,5-diethoxycarbonyl-1,4-dihydrocollidine. Biochem J 1972;126:1149-1160.

[4] Bonkowsky HL, Tschudy DP, Collins A, Doherty J, Bossenmaier I, Cardinal R, et al. Repression of the overproduction of porphyrin precursors in acute intermittent porphyria by intravenous infusions of hematin. Proc Natl Acad Sci USA 1971;68:2725-2729. doi: 10.1073/pnas.68.11.2725.

[5] Bishop DF. Two different genes encode delta-aminolevulinate synthase in humans: nucleotide sequences of cDNAs for the housekeeping and erythroid genes. Nucleic Acids Res 1990;18:7187-7188. doi: 10.1093/nar/ 18.23.7187.

[6] Watson C], Pierach CA, Bossenmaier I, Cardinal R. Postulated deficiency of hepatic heme and repair by hematin infusions in the "inducible" hepatic porphyrias. Proc Natl Acad Sci USA 1977;74:2118-2120. doi: 10.1073/ pnas.74.5.2118

[7] Gross U, Sassa S, Jacob K, Deybach JC, Nordmann Y, Frank M, et al. 5-Aminolevulinic acid dehydratase deficiency porphyria: a twenty-year clinical and biochemical follow-up. Clin Chem 1998;44:1892-1896.

[8] Whatley SD, Badminton MN. Acute Intermittent Porphyria. In: Pagon RA Adam MP, Ardinger HH, et al., eds. GeneReviews ${ }^{\circledR}$. Seattle (WA): University of Washington, 1993.

[9] Bissell DM, Wang B, Cimino T, Lai J. Hereditary Coproporphyria. In: Pagon RA, Adam MP, Ardinger HH, et al., eds. GeneReviews ${ }^{\mathbb{R}}$. Seattle (WA): University of Washington, 1993.

[10] Singal AK, Anderson KE. Variegate Porphyria. In: Pagon RA, Adam MP, Ardinger $\mathrm{HH}$, et al., eds. GeneReviews ${ }^{\mathrm{B}}$. Seattle (WA): University of Washington, 1993.

[11] Andersson C, Floderus Y, Wikberg A, Lithner F. The W198X and R173W mutations in the porphobilinogen deaminase gene in acute intermittent porphyria have higher clinical penetrance than R167W. A population-based study. Scand J Clin Lab Invest 2000;60:643-648. doi: 10.1080/003655 100300054891.

[12] von und zu Fraunberg M, Timonen K, Mustajoki P, Kauppinen R. Clinical and biochemical characteristics and genotype-phenotype correlation in Finnish variegate porphyria patients. Eur J Hum Genet 2002;10:649-657. doi: $10.1038 / \mathrm{sj}$.ejhg. 5200860

[13] Anderson KE, Bloomer JR, Bonkovsky HL, Kushner JP, Pierach CA, Pimstone $\mathrm{NR}$, et al. Recommendations for the diagnosis and treatment of the acute porphyrias. Ann Intern Med 2005;142:439-450. doi: 10.7326/0003-4819142-6-200503150-00010.

[14] Kauppinen R, von und zu Fraunberg M. Molecular and biochemical studies of acute intermittent porphyria in 196 patients and their families. Clin Chem 2002;48:1891-1900.

[15] Meissner PN, Dailey TA, Hift RJ, Ziman M, Corrigall AV, Roberts AG, et al. A R59W mutation in human protoporphyrinogen oxidase results in decreased enzyme activity and is prevalent in South Africans with variegate porphyria. Nat Genet 1996;13:95-97. doi: 10.1038/ng0596-95.

[16] Chretien S, Dubart A, Beaupain D, Raich N, Grandchamp B, Rosa J, et al. Alternative transcription and splicing of the human porphobilinogen deaminase gene result either in tissue-specific or in housekeeping expression. Proc Natl Acad Sci USA 1988;85:6-10. doi: 10.1073/pnas.85.1.6.

[17] Magnussen CR, Levine JB, Doherty JM, Cheesman JO, Tschudy DP. A red cell enzyme method for the diagnosis of acute intermittent porphyria. Blood $1974 ; 44: 857-868$.

[18] Lamon JM, Frykholm BC, Tschudy DP. Family evaluations in acute intermittent porphyria using red cell uroporphyrinogen I synthetase. J Med Genet 1979;16:134-139. doi: 10.1136/jmg.16.2.134.

[19] Daniell WE, Stockbridge HL, Labbe RF, Woods JS, Anderson KE, Bissell DM, et al. Environmental chemical exposures and disturbances of heme synthesis. Environ Health Perspect 1997;105(Suppl):37-53. doi: 10.1289/ ehp. 97105 s 137

[20] Whatley SD, Mason NG, Woolf JR, Newcombe RG, Elder GH, Badminton MN. Diagnostic strategies for autosomal dominant acute porphyrias: retrospective analysis of 467 unrelated patients referred for mutational analysis 
of the HMBS, CPOX, or PPOX gene. Clin Chem 2009;55:1406-1414. doi: 10.1373/clinchem.2008.122564.

[21] Nordmann Y, Puy H, Da Silva V, Simonin S, Robreau AM, Bonaiti C, et al. Acute intermittent porphyria: prevalence of mutations in the porphobilinogen deaminase gene in blood donors in France. J Intern Med 1997;242:213-217. doi: 10.1046/j.1365-2796.1997.00189.x.

[22] Pischik E, Kazakov V, Kauppinen R. Is screening for urinary porphobilinogen useful among patients with acute polyneuropathy or encephalopathy? J Neurol 2008;255:974-979. doi: 10.1007/s00415-008-0779-9.

[23] Liu YP, Lien WC, Fang CC, Lai TI, Chen W], Wang HP. ED presentation of acute porphyria. Am J Emerg Med 2005;23:164-167. doi: 10.1016/j.ajem .2004.03.013

[24] Litman DA, Correia MA. Elevated brain tryptophan and enhanced 5hydroxytryptamine turnover in acute hepatic heme deficiency: clinical implications. J Pharmacol Exp Ther 1985;232:337-345.

[25] Meyer UA, Schuurmans MM, Lindberg RL. Acute porphyrias: pathogenesis of neurological manifestations. Semin Liver Dis 1998;18:43-52. doi: 10.1055/ s-2007-1007139.

[26] Warren MJ, Cooper JB, Wood SP, Shoolingin-Jordan PM. Lead poisoning, haem synthesis and 5-aminolaevulinic acid dehydratase. Trends Biochem Sci 1998;23:217-221. doi: 10.1016/S0968-0004(98)01219-5.

[27] Costa CA, Trivelato GC, Pinto AM, Bechara EJ. Correlation between plasma 5-aminolevulinic acid concentrations and indicators of oxidative stress in lead-exposed workers. Clin Chem 1997;43:1196-1202.

[28] Sassa S, Fujita H, Kappas A. Succinylacetone and delta-aminolevulinic acid dehydratase in hereditary tyrosinemia: immunochemical study of the enzyme. Pediatrics 1990;86:84-86.

[29] Sardh E, Rejkjaer L, Andersson DE, Harper P. Safety, pharmacokinetics and pharmocodynamics of recombinant human porphobilinogen deaminase in healthy subjects and asymptomatic carriers of the acute intermittent porphyria gene who have increased porphyrin precursor excretion. Clin Pharmacokinet 2007;46:335-349. doi: 10.2165/00003088-20074604000006.

[30] Soonawalla ZF, Orug T, Badminton MN, Elder GH, Rhodes JM, Bramhall SR, et al. Liver transplantation as a cure for acute intermittent porphyria. Lancet 2004;363:705-706. doi: 10.1016/S0140-6736(04)15646-8.

[31] Magnussen CR, Doherty JM, Hess RA, Tschudy DP. Grand mal seizures and acute intermittent porphyria. The problem of differential diagnosis and treatment. Neurology 1975;25:121-125. doi: 10.1212/WNL.25.12.1121.

[32] Lamon JM, Frykholm BC, Hess RA, Tschudy DP. Hematin therapy for acute porphyria. Medicine 1979;58:252-269. doi: 10.1097/00005792197905000-00005.

[33] Tenhunen R, Tokola $O$, Linden IB. Haem arginate: a new stable haem compound. J Pharm Pharmacol 1987;39:780-786. doi: 10.1111/j.20427158.1987.tb05119.x.

[34] Krauss GL, Simmons OBE, Campbell M. Successful treatment of seizures and porphyria with gabapentin [see comments]. Neurology 1995;45:594-595. doi: $10.1212 /$ WNL.45.3.594.

[35] Taylor RL. Magnesium sulfate for AIP seizures [letter]. Neurology $1981 ; 31$ : 1371-1372. doi: 10.1212/WNL.31.10.1371-b.

[36] Bonkowsky HL, Sinclair PR, Emery S, Sinclair JF. Seizure management in acute hepatic porphyria: risks of valproate and clonazepam. Neurology 1980;30:588-592. doi: 10.1212/WNL.30.6.588.

[37] Pazvanska EE, Hinkov OD, Stojnovska LV. Uneventful propofol anaesthesia in a patient with acute intermittent porphyria. Eur J Anaesthesiol 1999;16: 485-492. doi: 10.1046/j.1365-2346.1999.00509.x.

[38] Pandey CK, Singh N, Bose N, Sahay S. Gabapentin and propofol for treatment of status epilepticus in acute intermittent porphyria. J Postgrad Med 2003; 49:285.

[39] Watson C], Bossenmaier I, Cardinal R. Acute intermittent porphyria. Urinary porphobilinogen and other Ehrlich reactors in diagnosis. JAMA 1961;175: 1087-1091. doi: 10.1001/jama.1961.63040120001010.

[40] Lamon J, With TK, Redeker AG. The Hoesch test: bedside screening for urinary porphobilinogen in patients with suspected porphyria. Clin Chem 1974;20:1438-1440.

[41] Pierach CA, Cardinal R, Bossenmaier I, Watson CJ. Comparison of the Hoesch and the Watson-Schwartz tests for urinary porphobilinogen. Clin Chem 1977;23:1666-1668.

[42] Davis JR, Andelman SL. Urinary delta-aminolevulinic acid. Arch Environ Health 1967;15:53-59. doi: 10.1080/00039896.1967.10664873.

[43] Deacon AC, Peters TJ. Identification of acute porphyria: evaluation of a commercial screening test for urinary porphobilinogen. Ann Clin Biochem 1998;35:726-732. doi: 10.1177/000456329803500604.

[44] Vogeser M, Stauch T. Evaluation of a commercially available rapid urinary porphobilinogen test. Clin Chem Lab Med 2011;49:1491-1494. doi: 10.1515 /CCLM.2011.605.

[45] Mattern SE, Tefferi A. Acute porphyria: the cost of suspicion. Am J Med 1999; 107:621-623. doi: 10.1016/S0002-9343(99)00305-8.

[46] Bonkovsky HL, Maddukuri VC, Yazici C, Anderson KE, Bissell DM, Bloomer JR, et al. Acute Porphyrias in the USA: Features of 108 Subjects from Porphyria
Consortium. Am J Med 2014;127:1233-1241. doi: 10.1016/j.amjmed.2014 .06 .036

[47] Laureno R, Karp BI. Myelinolysis after correction of hyponatremia. Ann Intern Med 1997;126:57-62. doi: 10.7326/0003-4819-126-1-199701010-00008.

[48] Dhar GJ, Bossenmaier I, Petryka ZJ, Cardinal R, Watson CJ. Effects of hematin in hepatic porphyria. Further studies. Ann Intern Med 1975;83:2030. doi: 10.7326/0003-4819-83-1-20.

[49] Bissell DM. Treatment of acute hepatic porphyria with hematin. ] Hepatol 1988;6:1-7. doi: 10.1016/S0168-8278(88)80456-2.

[50] Mendenhall DW. Instability of hematin solutions. N Engl J Med 1984;311: 539-540. doi: 10.1056/NEJM198408233110819.

[51] Goetsch CA, Bissell DM. Instability of hematin used in the treatment of acute hepatic porphyria. N Engl J Med 1986;315:235-238. doi: 10.1056/NEJM 198607243150406 .

[52] Anderson KE, Bonkovsky HL, Bloomer JR, Shedlofsky SI. Reconstitution of hematin for intravenous infusion. Ann Intern Med 2006;144:537-538. doi: 10.7326/0003-4819-144-7-200604040-00023.

[53] Mustajoki P, Tenhunen R, Tokola O, Gothoni G. Haem arginate in the treatment of acute hepatic porphyrias. Br Med J (Clin Res Ed) 1986;293: 538-539. doi: 10.1136/bmj.293.6546.538-a.

[54] McColl KE, Moore MR, Thompson GG, Goldberg A. Treatment with haematin in acute hepatic porphyria. Q J Med 1981;50:161-174.

[55] Herrick AL, McColl KE, Moore MR, Cook A, Goldberg A. Controlled trial of haem arginate in acute hepatic porphyria [see comments]. Lancet 1989;1: 1295-1297. doi: 10.1016/S0140-6736(89)92688-3.

[56] Bosch EP, Pierach CA, Bossenmaier I, Cardinal R, Thorson M. Effect of hematin in porphyric neuropathy. Neurology 1977;27:1053-1056. doi: 10.1212/WNL.27.11.1053.

[57] Dhar GJ, Bossenmaier I, Cardinal R, Petryka ZJ, Watson CJ. Transitory renal failure following rapid administration of a relatively large amount of hematin in a patient with acute intermittent porphyria in clinical remission. Acta Medica Scandinavica 1978;203:437-443. doi: 10.1111/j.09546820.1978.tb14903.x.

[58] Frei P, Minder EI, Corti N, Muellhaupt B, Geier A, Adams H, et al. Liver Transplantation because of Acute Liver Failure due to Heme Arginate Overdose in a Patient with Acute Intermittent Porphyria. Case Rep Gastroenterol 2012;6:190-196. doi: 10.1159/000338354.

[59] Daimon M, Susa S, Igarashi M, Kato T, Kameda W. Administration of heme arginate, but not hematin, caused anaphylactic shock. Am J Med 2001;110: 240. doi: 10.1016/S0002-9343(00)00720-8.

[60] Morris DL, Dudley MD, Pearson RD. Coagulopathy associated with hematin treatment for acute intermittent porphyria. Ann Intern Med 1981;95:700701. doi: 10.7326/0003-4819-95-6-700.

[61] Jones RL. Hematin-derived anticoagulant. Generation in vitro and in vivo. J Exp Med 1986;163:724-739. doi: 10.1084/jem.163.3.724.

[62] Anderson KE, Spitz IM, Bardin CW, Kappas A. A gonadotropin releasing hormone analogue prevents cyclical attacks of porphyria. Arch Intern Med 1990;150:1469-1474. doi: 10.1001/archinte.1990.00390190115018.

[63] Herrick AL, McColl KE, Wallace AM, Moore MR, Goldberg A. LHRH analogue treatment for the prevention of premenstrual attacks of acute porphyria. Q J Med 1990;75:355-363.

[64] Lamon JM, Frykholm BC, Bennett M, Tschudy DP. Prevention of acute porphyric attacks by intravenous haematin. Lancet 1978;2:492-494. doi: 10.1016/S0140-6736(78)92217-1.

[65] Singal AK, Parker C, Bowden C, Thapar M, Liu L, McGuire BM. Liver transplantation in the management of porphyria. Hepatology 2014;60: 1082-1089. doi: 10.1002/hep.27086.

[66] Dowman JK, Gunson BK, Mirza DF, Bramhall SR, Badminton MN, Newsome $\mathrm{PN}$, et al. Liver transplantation for acute intermittent porphyria is complicated by a high rate of hepatic artery thrombosis. Liver Transpl 2012;18: 195-200. doi: 10.1002/It.22345.

[67] Dowman JK, Gunson BK, Bramhall S, Badminton MN, Newsome PN. Liver transplantation from donors with acute intermittent porphyria. Ann Intern Med 2011;154:571-572. doi: 10.7326/0003-4819-154-8-201104190-00015.

[68] Seth AK, Badminton MN, Mirza D, Russell S, Elias E. Liver transplantation for porphyria: who, when, and how? Liver Transpl 2007;13:1219-1227. doi: 10.1002/It.21261.

[69] Yasuda M, Gan L, Chen B, Kadirvel S, Yu C, Phillips JD, et al. RNAi-mediated silencing of hepatic Alas 1 effectively prevents and treats the induced acute attacks in acute intermittent porphyria mice. Proc Natl Acad Sci USA 2014; 111:7777-7782. doi: 10.1073/pnas.1406228111.

[70] Unzu C, Sampedro A, Mauleon I, Alegre M, Beattie SG, de Salamanca RE, et al. Sustained enzymatic correction by rAAV-mediated liver gene therapy protects against induced motor neuropathy in acute porphyria mice. Mol Ther 2011;19:243-250. doi: 10.1038/mt.2010.210.

[71] Ridley A. The neuropathy of acute intermittent porphyria. Q J Med 1969;38: 307-333.

[72] Kauppinen R, Mustajoki P. Prognosis of acute porphyria: occurrence of acute attacks, precipitating factors, and associated diseases. Medicine (Baltimore) $1992 ; 71: 1-13$ 
[73] Jeans JB, Savik K, Gross CR, Weimer MK, Bossenmaier IC, Pierach CA, et al. Mortality in patients with acute intermittent porphyria requiring hospitalization: a United States case series. Am J Med Genet 1996;65: 269-273.

[74] Tishler PV, Woodward B, O'Connor J, Holbrook DA, Seidman LJ, Hallett M, et al. High prevalence of intermittent acute porphyria in a psychiatric patient population. Am J Psychiatry 1985;142:1430-1436.

[75] Jara-Prado A, Yescas P, Sanchez FJ, Rios C, Garnica R, Alonso E. Prevalence of acute intermittent porphyria in a Mexican psychiatric population. Arch Med Res 2000;31:404-408. doi: 10.1016/S0188-4409(00)00092-8.

[76] Patience DA, Blackwood DH, McColl KE, Moore MR. Acute intermittent porphyria and mental illness-a family study. Acta Psychiatr Scand 1994;89: 262-267. doi: 10.1111/j.1600-0447.1994.tb01511.x.

[77] Karbownik M, Tan D, Manchester LC, Reiter RJ. Renal toxicity of the carcinogen delta-aminolevulinic acid: antioxidant effects of melatonin. Cancer Lett 2000;161:1-7. doi: 10.1016/S0304-3835(00)00568-1.
[78] Marsden JT, Chowdhury P, Wang J, Deacon A, Dutt N, Peters TJ, et al. Acute intermittent porphyria and chronic renal failure. Clin Nephrol 2008;69:339346. doi: 10.5414/CNP69339.

[79] Bjersing L, Andersson C, Lithner F. Hepatocellular carcinoma in patients from northern Sweden with acute intermittent porphyria: morphology and mutations. Cancer Epidemiol Biomarkers Prev 1996;5:393-397.

[80] Andant C, Puy H, Faivre J, Deybach JC. Acute hepatic porphyrias and primary liver cancer [letter]. N Engl J Med 1998;338:1853-1854. doi: 10.1056/ NEJM199806183382518.

[81] Schneider-Yin X, van Tuyll van Serooskerken AM, Went P, Tyblewski W, Poblete-Gutierrez P, Minder EI, et al. Hepatocellular carcinoma in variegate porphyria: a serious complication. Acta Derm Venereol 2010;90:512-515. doi: 10.2340/00015555-0870.

[82] Sardh E, Wahlin S, Bjornstedt M, Harper P, Andersson DE. High risk of primary liver cancer in a cohort of 179 patients with Acute Hepatic Porphyria. J Inherit Metab Dis 2013;36:1063-1071. doi: 10.1007/s10545-012-9576-9. 